\title{
BERDING, Helmut, HELLER, Klaus, SPEITKAMP, Winfried, Krieg und Erinnerung. Fallstudien zum 19. und 20. Jahrhundert
}

\section{Anne Duménil}

\section{(2) OpenEdition}

1 Journals

Édition électronique

URL : http://journals.openedition.org/ifha/1214

DOI : 10.4000/ifha.1214

ISSN : 2198-8943

Éditeur

IFRA - Institut franco-allemand (sciences historiques et sociales)

Référence électronique

Anne Duménil, « BERDING, Helmut, HELLER, Klaus, SPEITKAMP, Winfried, Krieg und Erinnerung Fallstudien zum 19. und 20. Jahrhundert », Revue de l'IFHA [En ligne], Date de recension, mis en ligne le 01 janvier 2002, consulté le 22 septembre 2020. URL : http://journals.openedition.org/ifha/1214 ; DOI : https://doi.org/10.4000/ifha.1214

Ce document a été généré automatiquement le 22 septembre 2020.

(CIFHA 


\title{
BERDING, Helmut, HELLER, Klaus, SPEITKAMP, Winfried, Krieg und Erinnerung. Fallstudien zum 19. und 20. Jahrhundert
}

\author{
Anne Duménil
}

1 Issus d'une table ronde organisée en février 1999 par les chercheurs du Sonderforschungsbereich de l'université de Gießen, les articles de ce volume étudient le rôle des guerres dans la genèse et les formes d'expression de la mémoire collective.

2 Interrogeant les spécificités confessionnelles de la culture de guerre de 1870, C. RAK s'intéresse à l'expérience de guerre des aumôniers catholiques du diocèse de Rottenburg. S'ils affirment la légitimité d'un conflit conçu comme défensif, ils ignorent la notion de guerre rédemptrice et la justification, présente dans les écrits protestants, par l'argumentation historique. La comparaison des originaux et de la version éditée de leurs rapports révèle une hiérarchie catholique méfiante face aux pratiques œcuméniques du front et sensible à la concurrence entre confessions. Comparant les œuvres de Theodor Fontane, Gustav Freytag et Felix Dahn, R. KIPPER souligne que si la guerre franco-allemande fut perçue comme décisive dans la constitution de l'identité nationale et parut valider le topos de l'antinomie radicale entre Germains et Welsches, l'événement fut aussi l'objet d'élaborations mémorielles différenciées. Convaincu de la supériorité des mœurs allemandes, Fontane ne développe aucune conception essentialiste de la nation et privilégie des déterminismes historiques. À l'inverse, le roman Die Ahnen de Gustav Freytag inscrit la guerre dans une longue durée qui voit le peuple allemand, dépositaire de toutes les vertus de la germanité, accomplir cette fin supérieure de l'histoire : la formation d'un État-Nation où prévaut un ordre social et constitutionnel libéral. La prégnance de l'interprétation völkisch insère alors la guerre dans un système d'interprétation mythique.

3 Attentive, elle aussi, à la fonction de la littérature dans la formation de la mémoire collective, A. GÜMBEL montre comment le grand succès de Hans Grimm, Volk ohne 
Raum, paru en 1926, a alimenté un actif révisionnisme colonial. L'exposition de 1928 « Volk ohne Raum, Raum ohne Volk " révèle l'influence d'une œuvre qui dénonçait comme un " coup de poignard dans le dos " l'acceptation des clauses du traité de Versailles privant l'Allemagne de ses colonies, affirmait la nécessité de la révision et confortait ainsi les positions des adversaires de Weimar. Sans grande originalité, P. ALTER constate la considérable présence de la Grande Guerre dans la mémoire collective britannique. Analysant les projets allemands de monument national aux morts de la Grande Guerre et leur échec, B. ZIEMANN montre que l'absence d'un lieu central du souvenir des morts de la guerre, faute de consensus sur le site et la forme du monument, trahit moins le triomphe des particularismes que l'impossible accord sur la définition de la nation allemande. Quant au soldat inconnu, l'Allemagne fut un des rares pays à ne pas l'adopter, en dépit des efforts en ce sens des Reichsbanner. Pourtant, les droites nationalistes se sont emparées de ce symbole, qui pouvait paraître un emprunt à des cultures commémoratives étrangères, en le soumettant à un puissant détournement de sens. Dans ses interventions, Hitler s'identifia, de façon récurrente, au « soldat inconnu et sans nom » auquel il revenait de mener le combat pour la communauté du peuple.

4 Les articles de M. HOFFMANN et B. BONWETSCH montrent que, peu présentes dans l'immédiat après-guerre, la "Grande Guerre patriotique » et la victoire jouèrent, dès 1953 et plus encore à partir des années 60 , un rôle éminent dans la construction de la mémoire officielle soviétique. En dépit de l'inflation commémorative, l'étroite censure exercée par l'État et le parti accentuait le fossé entre mémoire officielle, héroïsante et aseptisée, mémoire officieuse, forgée notamment par la littérature contemporaine, et mémoire individuelle. Cet écart nourrit l'exigence, affirmée lors des intenses débats publics de la perestroïka, d'une histoire qui, levant les tabous du passé soviétique, ferait place à une représentation de la guerre plus conforme à l'expérience vécue des contemporains.

5 A. ECKERT souligne la spécificité de la politique de la mémoire au Cameroun : contrairement à la situation prévalant dans les autres nations subsahariennes, la phase de la lutte pour l'indépendance est occultée car le nouveau pouvoir n'en est pas issu. Ainsi, le régime du président Ahidjo, au pouvoir de 1958 à 1982, a tenté, non d'en entretenir le souvenir, mais d'en organiser l'oubli, au prix parfois d'une sévère répression de ceux qui souhaitaient évoquer la mémoire de la révolte de Douala en 1945, des manifestations de 1955 ou des leaders de l'Union des Populations du Cameroun, qui joua un rôle central dans le mouvement de rébellion. Le tournant des années 90, qui vit l'UPC être de nouveau autorisée, fit place à des débats nourris sur les conflits de décolonisation et le rôle des différents acteurs. Mais le processus qui aurait dû conduire à l'intégration de ces événements dans la mémoire nationale fut rapidement interrompu, l'arrêt du processus de démocratisation et la profonde crise économique et sociale conduisant à une " ethnicisation » de la mémoire.

6 W. SPEITKAMP souligne lui aussi un cas de refoulement mémoriel : alors que la rébellion Mau Mau, objet, au Kenya et ailleurs, d'un intense travail de mémoire, notamment à travers la publication de sources et le développement d'une histoire orale, a donné lieu à de nombreuses recherches - présentées dans leurs différentes étapes et dans une intéressante perspective critique, attentive à une approche anthropologique du témoignage -, la politique kenyane de la mémoire demeure fondée sur le slogan de Kenyatta « Forgive and forget » : elle constitue une instance de l'oubli, 
au service d'une politique de réconciliation. Le souvenir de la rébellion est intégré dans le passé national mais sans se voir conférer un rôle éminent ce que signale l'absence de monument commémoratif national, alors que les vétérans n'ont pas obtenu les avantages fonciers qu'aurait pu leur conférer le départ des colons.

7 Englobant une assez vaste période chronologique et des champs géographiques variés, tous ces articles illustrent l'intérêt d'une approche qui confronte des cultures de la mémoire élaborées dans des contextes très divers. On regrettera cependant que le volume ne fasse pas place à une analyse strictement comparative, le point ultime de la logique initiée ici.

Anne DUMÉNIL 